\title{
In Which Neonates Does Early Recombinant Human Erythropoietin Treatment Prevent Anemia of Prematurity? Results of a Randomized, Controlled Study
}

\author{
VASSILIKI SOUBASI, GEORGE KREMENOPOULOS. ELISABETH DIAMANDI, CHAIDO TSANTALI. \\ AND DIMITRIOS TSAKIRIS

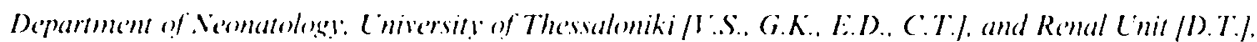 \\ Iippokration Hespital. Thessalomiki, (irece'
}

\begin{abstract}
ABSTRACI. To assess whether erythropoietin (EPO) treatment is safe and reduces the need for transfusion, we randomized 44 preterm infants to an EPO group and a comparable control $(\mathrm{CON})$ group. EPO $150 \mathrm{U} / \mathrm{kg}$ was given s.c. twice weekly for $6 \mathrm{wk}$ from the 1 st wh of life. Hematologic parameters, transfusion requirements, and growth were followed during therapy and for 6 mo thereafter. To better assess in which neonates EPO treatment was effective, we classified retrospectively the EPO and CON groups into uncomplicated neonates (EPO $\mathrm{A}: \boldsymbol{n}=9$, birth weight $=1247 \pm 126 \mathrm{~g}$, gestational age $=29.8 \pm 1.5$ wk; $\operatorname{CON} A: n=7$, birth weight $=1217 \pm 145 \mathrm{~g}$, gestational age $=29.9 \pm 1.5 \mathrm{wk}$ ) and neonates requiring artificial ventilation (EPO B: $n=16$, birth weight $=1169 \pm 249 \mathrm{~g}$, gestational age $=28.1 \pm 2 \mathrm{wk}$; CON B: $n=12$, birth weight $=1173 \pm 215 \mathrm{~g}$, gestational age $=28.3 \pm 2 \mathrm{wk}$ ). There were significant differences in reticulocytes between both uncomplicated and ventilated neonates in the EIPO group compared with respective control groups. However, the need for transfusion was significantly less in the uncomplicated EPO group (EPO A: $0.44 \pm 0.73$ versus CON A: $1.28 \pm 0.75, p<0 .(05)$ but not in the neonates on ventilation (EPO B: $8.25 \pm 5$ versus CON B: $7.75 \pm 3.7$ ). In conclusion, early EPO administration reduces the need for transfusion in uncomplicated premature neonates. Although stimulation of erythropoiesis was apparent in both uncomplicated and complicated neonates, the end-result of increased need for transfusion in complicated neonates was related to altered indication of transfusion. These infants probably require further or longer EPO administration after weaning from ventilation and improvement of clinical condition. (Pediatr Res 34: 675-679, 1993)
\end{abstract}

\section{Abbreviations}

EPO, erythropoietin

r-HuEPO, recombinant human erythropoietin

CON group, control group

BPD, bronchopulmonary dysplasia

$\mathrm{AOP}$, anemia of prematurity

$A$, uncomplicated

B, complicated

HbF, fetal hemoglobin

Received Octuber 26, 1992: accepted May 27, 1993.

Correspondence: Vassiliki Soubasi. Dept. of Neonatology. University of Thessaloniki. Hippokratio Hospital, Konstantinoupoleos 49. Thessalonihi 54642. Greece.
A transient, hyporegenerative anemia is a common problem among small, preterm infants, particularly those born at less than 31 wk of gestation $(1,2)$. This anemia is referred to as "anemia of prematurity," and is a normocytic. normochromic anemia with low reticulocyte counts, inappropriately low EPO serum levels; it is often apparent by the 3 rd or 4 th wk of life $(3,4)$. In addition, an early iatrogenic anemia occurs from blood samples that are taken for a variety of laboratory tests. Some infants tolerate this condition without apparent difficulty, but others are symptomatic, and this can be ameliorated by erythrocyte transfusion (5). Thus, very small premature neonates are among the most common of all patient groups to undergo extensive transfusion and the number of blood transfusions given in neonatal intensive care units has increased as the survival of very immature infants has improved (6). Red cell transfusion entails a considerable risk to small babies (7). Recently, r-HuEPO, a new therapeutic option in anemia, has been of great interest to neonatologists because it may prove to be an effective alternative to blood transfusions, inasmuch as infants with AOP have low EPO levels, reduced bone marrow erythroid precursors, and abundant EPO-sensitive erythroid progenitors $(8-10)$.

The results of the first clinical trials regarding the response and tolerance to EPO in infants have been published $(11-17)$. However, the original dosage. the time and mode of administration (i.e. preventive or therapeutic), and the treatment regimen have yet to be defined $(18-20)$.

We report a randomized controlled study of r-HuEPO carly preventive administration in small premature infants who were highly likely to require transfusions for AOP.

\section{MATERIALS AND METHODS}

Subjects. Forty-four premature infants entered a randomized. controlled trial after their parents gave informed consent in accordance with the ethics committee of our institution. The infants were randomly assigned to receive (EPO group: 25 neonates) or not receive (CON group: 19 neonates) r-HuEPO according to a schedule generated by a random-number table. The doctors in clinical charge were unaware of the treatment or control status of the babies.

Infants were eligible for the study if they fulfilled all the following criteria: 1) gestational age at birth $\leq 31 \mathrm{wk}:$ 2) birth weight $\leq 1500 \mathrm{~g} ; 3$ ) aged 1 to $7 \mathrm{~d}: 4$ ) no history of significant hemolytic disease caused by glucose 6-phosphate dehydrogenase deficiency or $\mathrm{ABO}$ or Rh incompatibility; and 5) clinical stability at entry as judged by the absence of electrolyte-acid base disturbances, absence of acquired or congenital infections, good oxygenation either in mechanical ventilation or not, and absence of seizures and hỵpertension. 
Given that EPO treatment was started during the lst wk of life, it was not possible to anticipate the probability of developing complications. For this reason, at the end of the therapy, to better assess in which neonates EPO treatment was effective, we classified the EPO and CON groups into uncomplicated $(A)$ and complicated (B) neonates. Neonates without or with minimal signs of respiratory distress and with no signs of sepsis were considered uncomplicated, whereas neonates requiring mechanical ventilation (respiratory distress syndrome, apnea, and sepsis) for more than $3 \mathrm{~d}$ were characterized as complicated.

Drug administration. We used r-HuEPO manufactured by Cilag A.G. (Zug. Switzerland) as a buffered solution containing $2000 \mathrm{U} / \mathrm{mL}$ of $\mathrm{r}-\mathrm{HuEPO}$. After $1: 1$ dilution with $0.9 \%$ saline solution, a solution of $1000 \mathrm{U} / \mathrm{mL}$ was obtained that was more suitable for administration to small infants. Starting at 3-7 d of life, r-HuEPO was given s.c. twice weekly up to $6 \mathrm{wk}$ of postnatal age at a dosage of $150 \mathrm{U} / \mathrm{kg}$ body weight per dose. All the patients had oral supplements of elemental iron $3 \mathrm{mg} / \mathrm{kg} / \mathrm{d}$ from the $15 \mathrm{th}$ $\mathrm{d}$ of life that were continued at the discretion of the attending neonatologist. The most common reason for temporarily discontinuing iron therapy was suspected sepsis or necrotizing enterocolitis. Infants initially were on total parenteral nutrition, consisting of carbohydrates $15 \mathrm{~g} / \mathrm{kg} / \mathrm{d}$, proteins $2 \mathrm{~g} / \mathrm{kg} / \mathrm{d}$, and fat 2 $\mathrm{g} / \mathrm{kg} / \mathrm{d}$. Thereafter, depending on their clinical condition, they received a special formula for premature neonates that contained $2 \mathrm{~g}$ of protein per $100 \mathrm{~mL}$. They also received $1 \mathrm{~mL}$ of multivitamins per $\mathrm{d}$ and vitamin $\mathrm{E}(5 \mathrm{U} / \mathrm{d})$ as part of the standard nursery care. In all infants, r-HuEPO therapy was administered in the hospital.

Laboratory and clinical momitoring. The following data were recorded before, during, and at completion of treatment, and at up to 6 mo of age: daily vital signs with blood pressures obtained with an automatic noninvasive oscillometric monitor (Dinamap 847. Criticon), number and duration of apneic episodes, bradycardias or tachycardias, daily weights, caloric intake, cerebral sonograms, and transfusion requirements. Transfusions were ordered by the clinicians caring for each infant without consulting the investigators, based on general guidelines for erythrocyte transfusions $(6,21)$. According to these guidelines, neonates who were well were transfused if their hematocrit was less than 0.25 combined with signs referable to their anemia, such as poor weight gain, persistent episodes of bradycardia or tachycardia, and apnea. Neonates with severe respiratory disease (BPD), particularly those requiring oxygen and/or ventilator support, received transfusions to maintain their hematocrit level at greater than $0.40(6)$.

Blood samples were obtained at entry, weekly, during the 6wk treatment, and thereafter at 3 and 6 mo of chronologic age for determination of hematocrit, $\mathrm{Hb}$ concentration, and complete blood cell counts including reticulocytes (percentage). thrombocytes, smear examinations, serum levels of ferritin, fetal Hb cytochemistry data by acid elution, and serum EPO levels by RIA (22). For reticulocyte and $\mathrm{Hb}$ F-containing erythrocyte counts, 2000 and 400 cells were counted, respectively, and all determinations were done blindly and in duplicate. Blood was obtained every Monday morning and EPO was given every Tuesday and Friday morning.

Statistical analysis. All statistical comparisons between treatment and control groups were performed with the $t$ test.

\section{RESULTS}

Patient characteristics and growth. There were no significant differences between the group of infants randomly assigned to receive or not receive $\mathrm{r}-\mathrm{HuEPO}$ in birth weight, gestational age, initial hematocrit, reticulocyte count, serum ferritin concentration, or serum erythropoietin concentration. Table I summarizes characteristics at entry.

In group $\mathrm{A}$, no children were mechanically ventilated. The mean time of full enteral feeding establishment was similar, 13 $\pm 5.4 \mathrm{~d}$ and $13.3 \pm 7.5 \mathrm{~d}$ in the EPO $\wedge$ and $C O N \wedge$ groups. respectively. In two neonates, one from each group, full enteral feeding was established on the 26th d of life because they had gastrointestinal problems (feeding intolerance, abdominal distension). A CON A neonate had an episode of urinary tract infection. Mean hospitalization time and rate of weight gain were similar for the two groups.

In group $\mathrm{B}$, there were no significant differences between EPO and control patients with respect to mechanical ventilation duration, total parenteral nutrition duration, mean nursing time, or rate for weight gain (Table 2). Two babies assigned to the EPO $B$ group died of $B P D$, one at 7 wk of age and the other at 4 mo of age; there was one control infant who also died of BPD. We observed no complications clearly attributable to EPO therapy.

At 3-6 mo of age, the rate of weight gain was similar in EPO and CON babies.

Ilematologic mesesurememts. There were no significant differences in hematocrit and $\mathrm{Hb}$ values between EPO and CON babies (both uncomplicated and complicated) at any time during the study from birth until 6 mo.

Pretreatment reticulocyte counts were similar at entry in all infants (Table 1). The initial fall in the reticulocyte count in both EPO and CON groups was followed by a marked increase in the EPO groups (both $A$ and $B$ ) compared with the CON groups (Figs. 1 and 2). Mean reticulocyte counts (\%) were significantly higher in EPO infants compared with control infants. At 3 and 6 mo of age, there were no differences between EPO and CON groups in reticulocyte counts (Figs. 1 and 2).

There were no significant changes in platelet counts in either group throughout the study period. Also, there were no significant differences between EPO and control patients with respect to total leukocyte counts or absolute neutrophil counts. No infant had an absolute neutrophil count of $<1 \times 10^{4} / \mathrm{L}$ during EPO treatment. Table 2 summarizes the hematologic parameters at the end of r-HuEPO therapy.

At entry, HbF levels were similar in both EPO and CON uncomplicated infants ( 94 and $100 \%$, respectively). The observed significant decrease in the level of $\mathrm{HbF}$ in the $\mathrm{CON} A$ group from the 4 th wk compared with the EPO $\wedge$ group was strongly correlated with the increased transfusion in the control babies. HbF levels in complicated neonates at the end of the study were very low, reflecting the high transfusion rate in this group. HbF in EPO B group was significantly higher at the 6th wh compared with the CON B group.

Blood sampling and transfiusions. Volumes of blood removed for laboratory tests and the amounts transfused in the studied groups are shown in Table 3 . There was a significant decrease in transfusions in EPO versus CON uncomplicated neonates (EPO A: $0.44 \pm 0.73$, CON $A: 1.28 \pm 0.75$ ). Only three of nine neonates in the uncomplicated EPO group received four transfusions compared with six of seven neonates of the control uncomplicated neonates, who received nine transfusions. One of the three EPO A neonates who received transfusions had two transfusions after the end of EPO treatment, one at the 7th wh and another one at the 11 th wk. In the complicated neonates, there was a high incidence of transfusion without any difference between EPO and $C O N$ neonates despite the significant increase of reticulocyte count in the EPO group (EPO B: $8.25 \pm 5$. CON B: 7.75 $\pm 3.7)$.

Sertum ferritin levels. At the beginning of the study, serum ferritin levels were similar in all patient groups. At the end of EPO treatment, ferritin levels in uncomplicated neonates were significantly lower compared with complicated neonates. In the EPO group of uncomplicated neonates, ferritin decreased significantly compared with the control group from the 3 rd wk. In complicated neonates, ferritin increased at the end of the study in both EPO and CON neonates, but the increase was lower in the EPO group (Figs. 3 and 4 ).

Serum EPO le'v'ls. Mean EPO levels at entry, which was 3-7 $\mathrm{d}$ after birth, were similar in all study patients $(10.5-14.7 \mathrm{U} / \mathrm{L})$. 
Table 1. Pretreatment characteristics of study infants*

\begin{tabular}{|c|c|c|c|c|}
\hline & \multicolumn{2}{|c|}{ Uncomplicated neonates } & \multicolumn{2}{|c|}{ Complicated neonates } \\
\hline & EPO & $\mathrm{CON}$ & EPO & CON \\
\hline No. of patients & 9 & 7 & 16 & 12 \\
\hline Birth weight (g) & $1247 \pm 126$ & $1217 \pm 145$ & $1169 \pm 249$ & $1173 \pm 215$ \\
\hline Gestational age (wk) & $29.8 \pm 1.5$ & $29.9 \pm 1.5$ & $28.1 \pm 2.0$ & $28.3 \pm 2.0$ \\
\hline Hematocrit & $0.46 \pm 0.01$ & $0.48 \pm 0.03$ & $0.45 \pm 0.05$ & $0.48 \pm 0.08$ \\
\hline Reticulocyte count & $0.11 \pm 0.07$ & $0.12 \pm 0.04$ & $0.11 \pm 0.04$ & $0.11 \pm 0.06$ \\
\hline Ferritin $(\mu \mathrm{g} / \mathrm{L})$ & $222 \pm 243$ & $206 \pm 113$ & $212 \pm 137$ & $2.48 \pm 128$ \\
\hline Serum EPO (U/L) & $14.6 \pm 16$ & $10.5 \pm 10$ & $16.5 \pm 22$ & $12.1 \pm 5.9$ \\
\hline
\end{tabular}

* Values are expressed as mean $\pm \mathrm{SD}$.

Table 2. Characteristics of infants at end of EPO treatme'nt*

\begin{tabular}{lccccc} 
& \multicolumn{2}{c}{ Uncomplicated neonates } & \multicolumn{2}{c}{ Complicated neonates } \\
\cline { 2 - 5 } & EPO & CON & 7 & EPO & 12 \\
No. of patients & $9.29 \pm 0.03$ & $0.27 \pm 0.05$ & & 16 & $0.31 \pm 0.06$ \\
Hematocrit & $91 \pm 10$ & $86 \pm 15$ & $99 \pm 21$ & $0.28 \pm 0.09$ \\
Hb $(\mathrm{g} / \mathrm{L})$ & $0.076 \pm 0.016$ & $0.054 \pm 0.036$ & $0.043 \pm 0.026$ & $0.025 \pm 0.017$ \\
Reticulocyte count & $9.4 \pm 0.3$ & $11.6 \pm 2.6$ & $12.3 \pm 6.1$ & $10.6 \pm 4.9$ \\
Leukocytes $\left(\times 10^{4} / \mathrm{L}\right)$ & $419 \pm 155$ & $33.4 \pm 85.6$ & $257 \pm 186$ & $259 \pm 120$ \\
Platelets $\left(\times 10^{4} / \mathrm{L}\right)$ & $11.3 \pm 14.3$ & $5.13 \pm 5.2$ & $11.1 \pm 11.8$ & $8.9 \pm 6.9$ \\
Serum EPO $(\mathrm{U} / \mathrm{L})$ & $1685 \pm 167$ & $1806 \pm 172$ & $1379 \pm 354$ & $1399 \pm 308$ \\
Weight $(\mathrm{g})$ & $11.0 \pm 6.2$ & $9.4 \pm 4.9$ & $31.5 \pm 18.7$ & $35.9 \pm 11.3$ \\
TPN $(\mathrm{d})$ & &
\end{tabular}

* Values are expressed as mean \pm SD. TPN, total parenteral nutrition.

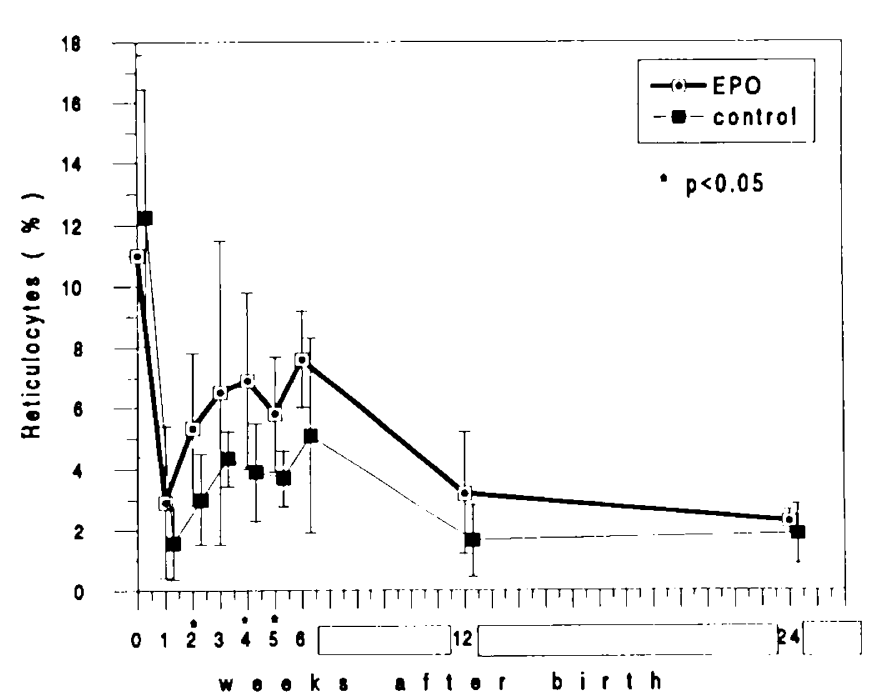

Fig. 1. Reticulocytes (\%) in uncomplicated neonates (conversion factor for SI, 0.01).

In the EPO groups, levels were slightly elevated during the study compared with control groups, but the differences were not significant. An increase was observed in the EPO uncomplicated group at the 2nd wk and at the 2nd and 3rd wk in the EPO complicated groups. After 6 wk of therapy, the mean EPO value was $11 \mathrm{U} / \mathrm{L}$ in EPO A, $5 \mathrm{U} / \mathrm{L}$ in $\operatorname{CON~A,~} 11 \mathrm{U} / \mathrm{L}$ in EPO B, and $9 \mathrm{U} / \mathrm{L}$ in CON B groups (Table 2). Subsequently, at 3 and 6 mo there were no significant differences in EPO levels between treated and control infants, indicating that treatment with $r$ HuEPO had no effect on subsequent EPO production. In four infants from the EPO complicated group, we observed very high values $(150-300 \mathrm{U} / \mathrm{L})$; in two of those infants, the high values were associated with exchange transfusions that were performed for sepsis.

\section{DISCUSSION}

In healthy, premature neonates, red blood cell transfusions are usually administered between the 3rd wk of life and hospital

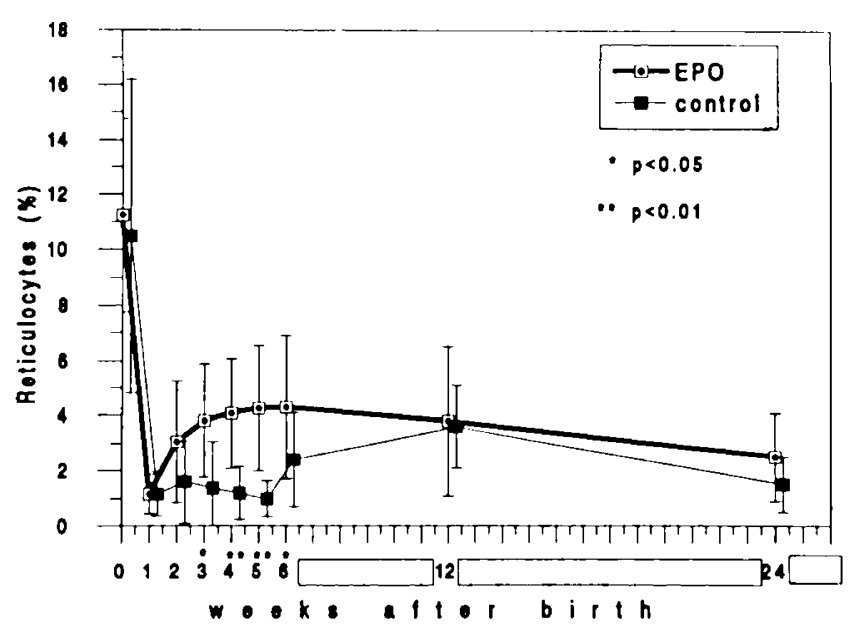

Fig. 2. Reticulocytes $(\%)$ in complicated neonates (conversion factor for Sl, 0.01).

discharge to treat the hyporegenerative normocytic normochromic AOP (23). It has been suggested that AOP is caused by selective deficiency of EPO. The hypothesis that AOP is the result of defective response of erythroid progenitors to EPO plus deficient generation of multiple erythropoietic factors was excluded by studies of Shannon 't al. (8) and Rhondeau et al. (9). They found normal responsiveness to EPO of burst-forming units-erythroid and colony-forming units-erythroid from verylow-birth-weight infants; also, the biologic activities of other factors responsible for early erythroid production, IL-3 and granulocyte-macrophage colony-stimulating factor, were not reduced in infants with AOP (24).

In our study, the favorable effect of EPO on erythropoiesis is apparent from the early significant increase in the reticulocyte count in both EPO groups (complicated and uncomplicated) compared with the control groups, but the need for transfusions was reduced only in uncomplicated EPO neonates. The levels of reticulocytes in the uncomplicated $\mathrm{CON}$ group were higher spontaneously than in the EPO complicated group. This finding most 
Table 3. Blood balance data during EPO treatmem*

\begin{tabular}{|c|c|c|c|c|}
\hline & \multicolumn{2}{|c|}{ Uncomplicated neonates } & \multicolumn{2}{|c|}{ Complicated neonates } \\
\hline & EPO & $\mathrm{CON}$ & $\mathrm{EPO}$ & $\mathrm{CON}$ \\
\hline No. of patients & 9 & 7 & 16 & 12 \\
\hline Phlebotomies (mL) & $20.7 \pm 3.4$ & $21.1 \pm 3.2$ & $66.3 \pm 18.3$ & $64.4 \pm 18.5$ \\
\hline Transfusions (mL) & $5.5 \pm 1.1 \dagger$ & $26.4 \pm 15.1$ & $83.3 \pm 35$ & $84.75 \pm 45.1$ \\
\hline
\end{tabular}

* Values are expressed as mean $\pm \mathrm{SD}$.

$+p<0.01$ is uncomplicated CON neonates.

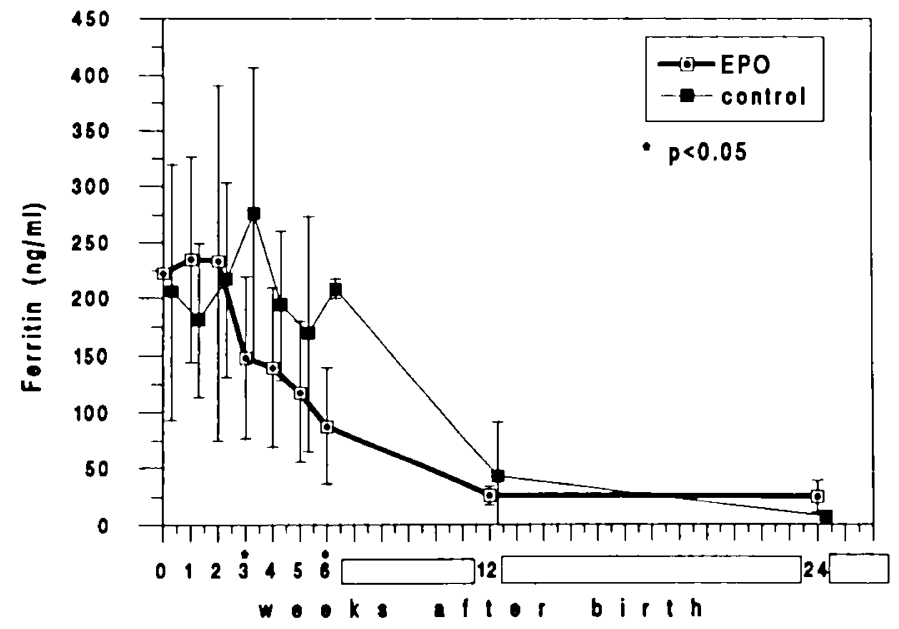

Fig. 3. Serum ferritin levels $(\mathrm{ng} / \mathrm{mL}$, conversion factor 1.00 for $\mu \mathrm{g} /$ $\mathrm{L})$ in uncomplicated neonates.

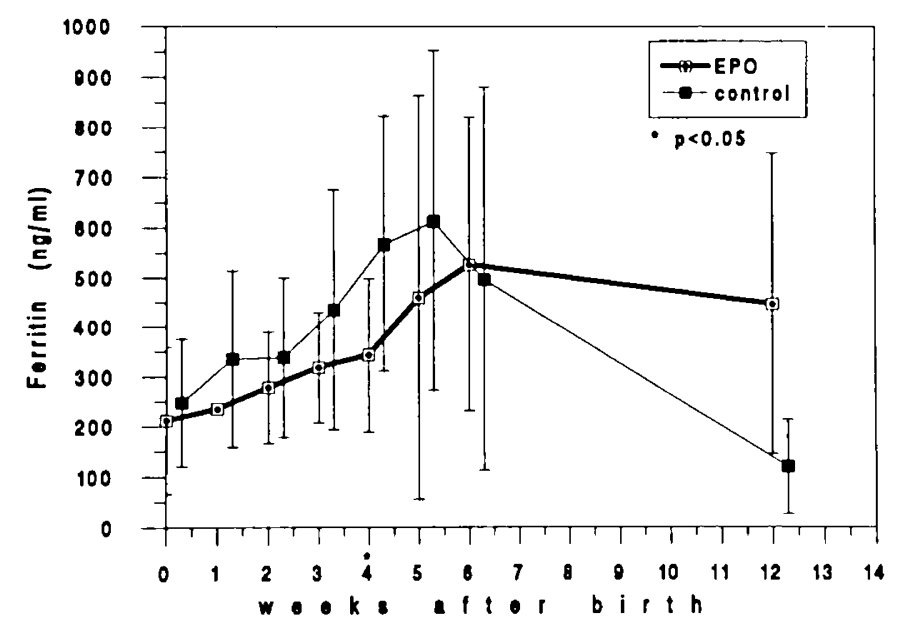

Fig. 4. Serum ferritin levels (ng/mL, conversion factor 1.00 for $\mu \mathrm{g}$ / $\mathrm{L}$ ) in complicated neonates.

likely was caused by the increased number of transfusions and possible infections that inhibited erythropoiesis in the complicated group. In complicated EPO neonates with respiratory problems, the end result of increased need for transfusions was related to altered indication for transfusion. In these neonates, it is customary to maintain hematocrit levels higher than $0.40(6)$. They also have large phlebotomy needs, which might limit or obscure their response to EPO (10). Shannon et al. (12), in a placebo-controlled study with mean age at entry $22 \mathrm{~d}$, administered r-HuEPO to 20 small, premature infants who were highly likely to require erythrocyte transfusions for AOP. They, despite the observed reticulocytosis did not find reduced need for transfusions. The heterogeneity of patients in their study is a possible explanation for this finding. However, our study was designed to give EPO in a preventive rather than therapeutic mode. The transfusion limit of hematocrit 0.40 explains the low reticulocyte curve of the complicated control group, because such a high limit will depress erythropoiesis even in adults.

Ohls and Christensen (13), like us, administered EPO in a higher dose to treat anemia in 20 infants, and their results are comparable to ours. All their neonates had at least one transfusion before the entry into the study. Probably with preventive EPO administration the neonates would not need any transfusion, because the end goal of EPO therapy is to reduce transfusions as much as possible because of their side effects. Such a goal is attractive, because $3 \%$ of infants who undergo transfusion have adverse effects (7). In our study, one of the three neonates in the uncomplicated EPO group who received transfusions had two transfusions after the end of EPO treatment. Probably the duration of therapy for $6 \mathrm{wk}$ is not ideal, and it should be altered according to individual clinical needs and laboratory findings. This is more likely the case for the complicated neonates, who should be treated with EPO until after weaning from ventilation and improvement of clinical condition (25).

The HbF values can be explained by the number of transfusions, but the increase of $\mathrm{HbF}$ after a fall of the initial values and the significantly higher $\mathrm{HbF}$ values in the EPO complicated group versus the CON B group could be due to the effect of EPO in the pattern of synthesized $\mathrm{Hb}(26)$. This observation should be elucidated by further studies.

Another sign indicative of the hemopoietic effect of $r-H u E P O$ is the gradual decline in serum ferritin levels in EPO groups compared with the CON groups that reflects the rapid mobilization of iron stores. Our results are in agreement with the results reported by Halperin et al. (11). We did not carry out any studies of iron balance because we tried to minimize blood sampling. Although serum ferritin levels were lower in the EPO-complicated group compared with the control, a gradual increase of ferritin in both EPO and CON complicated groups that was due to the high incidence of transfusion was observed.

Regarding the serum EPO levels, there was no significant increase in serum EPO in the treated groups compared with the control infants not receiving the medication. There are two reasons for the lack of such an increase in serum EPO levels. First, in premature infants, low endogenous production of erythropoietin relative to the degree of anemia has been documented $(27,28)$, and serum EPO levels are lower in the first 2 mo than at any other time in life (29). Premature infants are similar to chronic renal failure patients in that they have a limited capacity to raise their EPO production sufficiently to compensate for their anemia (30). Second, according to pharmacokinetic studies of EPO in children and adults with renal failure, an association between the timing and the route of administration (i.v. or s.c.) and serum EPO levels appears to exist, inasmuch as s.c. delivery resulted in serum values that peaked at $10 \mathrm{~h}$ and thereafter declined slowly with a $t_{1 / 2}$ of $21.1 \pm 4.5 \mathrm{~h}(31,32)$. In our study, there was an interval of about $72 \mathrm{~h}$ between EPO administration and blood sampling.

Erythropoietin in a dosage of $300 \mathrm{U} / \mathrm{kg} / \mathrm{wk}$ had no adverse effects on leukocytes and thrombocytes. This observation is valuable, especially in uncomplicated neonates, because the course of these neonates was not associated with any problems that can influence leukocytes and platelets. Ohls and Christensen (13) could not clarify the mechanism responsible for neutropenia that was observed after r-HuEPO with studies in bone marrow 
aspiration. The marked increase in erythropoiesis was not associated with depletion of either neutrophil reserves or granulocytemacrophage colony-forming unit concentrations.

In summary, we assessed the possibility of prevention of AOP by early administration of $\mathrm{r}-\mathrm{HuEpo}$ in a controlled trial. It seems that early administration of $r-H u E p o$ prevents $A O P$ in uncomplicated neonates. Because we cannot differentiate from birth which premature neonates would have problems, in our opinion, all small, premature neonates should be given $r-H u E P O$ as a part of their standard treatment. This speculation requires further support from larger controlled studies.

Acknowledgments. The authors thank Dr. A. Vizandiadis for kindly providing laboratory facilities to measure EPO levels, which were carried out by V. Aletra. We also thank Dr. C.A.J. Wardrop for critical comments on this manuscript.

\section{REFERENCES}

1. Stockman JA 1986 Anemia of prematurity. Current concepts in the issue of when to transfuse. Pediatr Clin North Am 33:111-128

2. Brown MS, Berman ER, Luckey 1990 Prediction of the need for transfusion during anemia of prematurity. J Pediatr 116:773-778

3. Wardrop CAJ. Holland BM. Veale KEA. Jones JG. Gray OP 1978 Nonphysiologic anemia of prematurity. Arch Dis Child 53:855-860)

4. Keves W'G, Donohue PK. Spivak JL. Jones Jr. MD. Oski FA 1989 Assessing the need for transfusion of premature infants and the role of hematocrit. clinical signs, and erythropoietin level. Pediatrics $84: 412-417$

5. Ross MP. Christensen RD. Rothstein G 1989 A randomized trial to develop criteria for administering erythrocyte transfusions, to anemic preterm infunts 1 to 3 months of age. J Perinatol $246-253$

6. Strauss RG 1991 Transfusion therapy in neonates. Am J Dis Child 145:904911

7. Hudson I. Cooke A, Holland A. Jones JG. Turner T. Wardrop CAJ 1990) Red cell volume and cardiac output in anaemic preterm infants. Arch Dis Child 65:672-675

8. Shannon KM, Naylor GS. Torkildson JC 1987 Circulating erythroid progenitors in the anemia of prematurity. N Engl J Med 31:728-733

9. Rhondeau SM, Christensen RD. Ross MP'. Rothstein G. Simmons MA 1988 Responsiveness to recombinant human erythropoietin of marrow erythroid progenitors from infants with the "anemia of prematurity." J Pediatr 112:935-940

10. Shannon KM. Mentzer WC, Abels RI, Freeman P. Newton N. Thompson D. Sniderman S, Ballard R, Phibbs RII 1990 Recombinant human erythropoietin ( $r-H u E P O)$ in anemia of prematurity (AOP): preliminary results of a double-blind placebo controlled pilot study. Pediatr Res 27:269 A(abstr)

11. Halperin DS. Wacker P. Lacourt G 1990 Effects of recombinant human erythropoietin in infants with the anemia of prematurity: a pilot study. J Pediatr 116:779-786

12. Shannon KM. Mentzer WC, Abels RI, Freeman P. Newton N, Thompson D, Sniderman S. Ballard R, Phibbs RH 1991 Recombinant human erithropoietin in the anemia of prematurity: results of a placebo-controlled pilot study. J Pediatr 118:949-955
13. Ohls RK. Christensen R 1991 Recombinant erythropoietin compared with erythrocyte transfusion in the treatment of anemia of prematurity. J Pediatr 119:781-788

14. Beck D. Masserey E, Mever M. Calame A 1991 Weekly intravenous administration of recombinant human erythropoietin in infants with anemia of prematurity. Eur J Pediatr 150:767-772

15. Soubasi V. Kremenopoulos G. Tsandali C Mastrogiani S, Kyriakidis G. Tsakiris D 1991 Effect of recombinant human ervthropoietin (EPO) in premature neonates: preliminary results of a double blind control trial. Pediatr Res 30:106(abstr)

16. Shannon KM, Mentzer WC, Abels RI, Wertz M. Thayer-Moriyama J Li WY. Decelle S. Phibbs RH 1992 Enhancement of ervthropoiesis by recombinant human erythropoietin in low birth weight infants: a pilot study. $J$ Pediatr 120:586-592

17. Halperin DS. Felix M. Wacker P. Lacourt G, Babel JF, Wyss M1 1992 Recombinant human ervthropoietin in the treatment of infants with anemia of prematurity. Eur J Pediatr 151:661-667

18. Obladen M, Maier R, Segerer H. Grauel EL, Holland B.M. Stewart G. Jorch G, Rabe H, Linderkamp O, Hoffmann HG, Houghton I: Hermann $Z$ Scigalla P. Wardrop C 1991 Efficacy and safety of recombinant human erythropoictin to present the anemias of prematurity. In: Gurland HJ, Moran J. Samtleben W. Scigalla P. Wieczorek L. (eds) Erythropoictin in Renal and Non-Renal Anemias. Contrib Nephrol 88:314-326

19. Stewart G, Holland B, Turner TL, Wardrop CAJ 1991 Erythroposictin in preterm infants: does it work? Br J Hacmatol 77(Suppl 1):4(abstr)

20. Carniclli V. Montini G. Dariol R. Dallamico R. Cantarutti F 1992 Effect of high doses of human recombinant erythropoietin on the need for blood transfusions in preterm infants. J Pediatr 121:98-102

21. Klaus MH, Fanaroff AA 1986 Care of the High Risk Neonate. 3rd Ed. W'B Saunders Co. Philadelphia

22. Egrie JC, Cotes PM, Lane J. Gaines Das RE. Tan RC 1987 Development of radioimmunoassays for human erythropoietin using recombinant erythropoietin as tracer immunogen. J Immunol Methods 99:325-341

23. Stockman JA 1988 Erythropoietin: off again on again. J Pediatr 112:906-908

24. Ohls RO, leichty KW. Turner MC. Kimura RE. Christensen RD 199() Erythroid "bursi promoting" activity in serum of patients with the anemia of prematurity. J Pediatr 1 16:786-789

25. Christensen RD. Hunter DD. Goodell H, Rothstein G 1992 Evaluation of the mechanism causing anemia in infants with bronchopulmonary dysplasia. $J$ Pediatr 120:593-598

26. Bard H 1992 Hypoxemia and increase fetal hemoglobin synthesis during the perinatal period. Semin Perinatol 16:191-195

27. Brown MS, Garcia JF, Phibbs RH, Dallman PR 1984 Decreased response of plasma immunoreactive erythropoietin to "available oxygen" in anemia of prematurity. J Pediatr 105:793-798

28. Stockman III JA. Gracher JE, Clark DA. McClellan K. Garcia JF. Kavey REW 1984 Anemia of prematurity: determinants of the erythropoietin response. I Pediatr 105:786-79)?

29. Eckardt KU, Hartmann W, Vetter U. Pohlandt F. Burghardt R. Kurtz A 199( Serum immunoreactive erythropoietin of children in health and discase. Eu J Pediatr 149:459-46:

30. Erslev A 1991 Erythropoietin. N Engl J Med 324:1339-134t

31. Evans JHC. Brocklebank JT, Bowmer CJ. Ng PC 1991 Pharmacokinetics of recombinant human erythropoietin in children with renal failure. Nephrol Dial Transplant 6:709-714

32. McDougall IC. Neubert P. Coles GA, Roherts DE, Dharmasena AD. Williams JD 1989 Pharmacokinetics of recombinant human erythropoictin in patients on continuous ambulatory peritoneal dialysis. Lancet 1:425-427 